\title{
Daily fluctuations in transit and jobs availability: A comparative assessment of time-sensitive accessibility measures
}

\section{Geneviève Boisjoly}

School of Urban Planning

McGill University*

E-mail: genevieve.boisjoly@mail.mcgill.ca

\author{
Ahmed El-Geneidy \\ School of Urban Planning \\ McGill University* \\ E-mail: ahmed.elgeneidy@mcgill.ca \\ * McGill University \\ Suite 400, 815 Sherbrooke St. W. \\ Montréal, Québec, H3A 2K6 \\ Canada \\ Tel.: 514-398-8741 \\ Fax: 514-398-8376
}

\section{6}

For Citation please use: Boisjoly, G. \& El-Geneidy, A. (2016). Daily fluctuations in transit and jobs availability: A comparative assessment of time-sensitive accessibility measures. Journal of Transport Geography, 52, 73-81. 


\section{ABSTRACT}

Accessibility to jobs by transit is increasingly incorporated into transportation and land-use planning objectives, as it is proven to be a relevant indicator for assessing land-use and transport performance. With a rise in time-sensitive accessibility measures, choosing the appropriate measure is increasingly challenging for engineers, planners and policy-makers. This research presents a comparative analysis of three accessibility measures, two of which are time-sensitive. Relative accessibility measures are generated for five time periods based on a) constant transit service and number of jobs (constant); b) variable transit service and constant number of jobs (static) and c) variable transit service and variable number of jobs available (dynamic). The measures are first assessed by incorporating them into a transit mode share model. Interestingly, findings show that all three measures behaved similarly in the three regression models. Furthermore, all accessibility measures are found to be highly correlated. The study suggests that the most commonly used accessibility measure (constant measure at $8 \mathrm{am}$ ) is representative of the relative accessibility (static or dynamic) over the course of the day and is thus appropriate and meaningful to be used by policy-makers, engineers and planners.

Keywords: Dynamic accessibility, Static accessibility, Time-sensitive measures, Transit variability 


\section{INTRODUCTION}

Accessibility is increasingly incorporated into transportation and land-use planning objectives

(Geurs, Krizek, \& Reggiani, 2012; Handy, 2008; Lucas, 2012; Manaugh, Badami, \& El-Geneidy, 2015; Preston \& Rajé, 2007), as it is proven to be a relevant indicator for promoting equitable transport systems (Martens, Golub, \& Robinson, 2012), sustainable urban transportation (Banister, 2008; Boschmann \& Kwan, 2008; Handy, 2008) and social inclusion among disadvantaged groups (Lucas, 2012; Preston \& Rajé, 2007). Increasing accessibility by transit allows meeting the needs of individuals while reducing automobile dependence (Handy, 2002). For engineers and planners, choosing appropriate metrics is central in order to evaluate desired goals and develop effective policies (Geurs \& van Wee, 2004; Handy \& Niemeier, 1997). A plethora of accessibility measures have been developed (Geurs \& van Wee, 2004; Handy \& Niemeier, 1997; Páez, Scott, \& Morency, 2012), with a trend towards more detailed and complex approaches (Geurs et al., 2012). Namely, recent research seeks to address the fluctuation in accessibility by transit that may occur over the day due to variations in service (Anderson, Owen, \& Levinson, 2012; El-Geneidy et al., 2016; Farber, Morang, \& Widener, 2014; Wangtu, Ding, Zhou, \& Li, 2015). Various approaches are put forward, based on different methodological and conceptual basis, and addressing different levels of complexity.

Given recent theoretical developments and a growing interest for applicable accessibility metrics, this methodological study explores whether time-sensitive measures of location-based accessibility to jobs by transit throughout the day provide a more appropriate measure of accessibility than the constant ones. By doing so, this research seeks to address the gap between accessibility research and its practical applications. The research setting is the Greater Toronto Hamilton Area (GTHA). Building on previous studies (El-Geneidy et al., 2016; Fan, Guthrie, \& Levinson, 2012; Legrain, Buliung, \& El-Geneidy, 2015), we generate three accessibility measures 
for five daily time periods. The first accessibility measure is constant over the day, while the two other measures take into account the fluctuations in transit and job availability during the day. Using one data set, this study compares the three different measures and is of relevance to engineers and planners who want to balance between the accuracy and the simplicity of a measure. This research, although based on one region, provides methodological insight that can be relevant to other regions.

\section{LITERATURE REVIEW}

\section{Accessibility}

In transportation planning, accessibility is largely defined as the potential of an individual to reach opportunities (Preston \& Rajé, 2007). While mobility studies are mainly interested in travel speed, accessibility includes a broader range of factors that affect the capacity or the ease of reaching a location. Based on an extensive literature review of accessibility definitions, Geurs \& van Wee (2004) identify four components of accessibility: the transport component, the land-use component, the individual component and the temporal component. The transport component, widely studied in mobility and accessibility studies, is related to the transport infrastructure and is usually mode specific. The land-use component refers to the location and the characteristic of opportunities or the location of people. Most studies focus on opportunities such as jobs, health services and shops. The individual component reflects the personal characteristics that might affect one's travel needs or capacity, including factors such as age, gender, car ownership, education, household composition and income. The last dimension is the temporal component, including the availability of opportunities across the day (example, opening hours of shops), the individual's schedule, as well as the transit schedule. 


\section{Accessibility Measures}

Given the wide scope of factors affecting accessibility, measures of accessibility are also diverse. The measures of accessibility can be person-based, measuring the opportunities at the individual level, or location-based, measuring the number of opportunities accessible from one location (Geurs \& van Wee, 2004; Miller, 2005; Owen \& Levinson, 2015). Person-based accessibility accounts for individual factors affecting one's ease of reaching its desired destination, whereas location-based accessibility presents aggregated measures. While location-based measures do not capture the individual component of accessibility, they allow assessing it at the regional scale and are thus most commonly used by policy-makers (Dodson, Gleeson, Evans, \& Sipe, 2007). Because of its planning relevance, location-based accessibility is the focus of our study. The most common measure of location-based accessibility is the cumulative-opportunity measure (Geurs \& van Wee, 2004). This method counts the number of opportunities that can be accessed from one location within a given travel time. A second common method is the gravitybased method, first introduced by Hansen (1959), which takes into account all opportunities available in the region and then discounts them based on the travel time from the origin. While the cumulative-opportunity measure is simpler, the gravity-based measure provides an estimation that better reflects reality.

Accessibility measures can be translated into relative accessibility indicators to compare the levels of accessibility across groups or modes (Niedzielski \& Boschmann, 2014; Páez, Mercado, Farber, Morency, \& Roorda, 2010) or across a region (Manaugh \& El-Geneidy, 2012;

Widener, Farber, Neutens, \& Horner, 2015). Zonal relative accessibility allows policy-makers to assess the geographic distribution of opportunities and transportation services (Handy \& Niemeier, 1997). 


\section{Accessibility by transit}

As transit gained importance in accessibility research, numerous studies assessed accessibility to transit (Moniruzzaman \& Páez, 2012; Olszewski \& Wibowo, 2005; Zielstra \& Hochmair, 2011), counting for example the number of transit stops within a specified walking distance. While these measures provide an indication of the presence of transit service in an area, they do not assess the quality of this service to reach desired destinations. Accessibility by transit to opportunities is hence increasingly researched as it provides a more comprehensive measure regarding the quality of transit service in a region.

Typical measures of accessibility by transit primarily focus on the transport component (transport infrastructure and transit service availability) and the land-use component (location of homes, workplaces, health services, shops, etc.). Accessibility by transit is based on travel time, calculated using the transport network characteristics, and on the location of opportunities and home locations. Measures are typically based on a single departure time, using a fixed number of opportunities, without considering opening hours of services, or, in the case of jobs, starting time (Owen \& Levinson, 2015).

\section{Time-Sensitive Measures}

While temporal factors are predominant in studies of person-based accessibility (Miller, 2005), using for example the space-time prism, first developed by Hagerstrand (1970), they are marginal in location-based accessibility studies. Although technical progress has been made for calculating travel time by transit, namely with the use of the General Transit Feed Specification (GTFS) (Lei \& Church, 2010; Owen \& Levinson, 2015), daily fluctuations are seldom taken into account when measuring accessibility (Owen \& Levinson, 2015). Furthermore, very few studies have included 
the combined influence of spatial and temporal factors in accessibility by transit (Dodson et al., 2007).

Nevertheless, growing research highlights the importance of developing measures that are sensitive to temporal constraints (Anderson et al., 2012; Dodson et al., 2007; El-Geneidy et al., 2016). In this regard, some studies have attempted to address accessibility daily fluctuations by taking into account variations in transit service. A first stream of research assesses variation of transit service based on fluctuation of the demand (Polzin, Pendyala, \& Navari, 2002; Wangtu et al., 2015). Most commonly, studies investigate transit service variation with regard to transit schedules. Mavoa et al. (2012) and Dill et al. (2013) address fluctuations in transit service by adding a transit frequency variable together with the accessibility measure while Dodson et al. (2007) measure transit frequency at different times of the day to assess transit service. Other studies take into account the daily fluctuations of transit service by basing the accessibility measures on various departure times. Fan et al. (2012) calculate travel time at every hour of the day and provide a daily accessibility based on average hourly travel times. Owen \& Levinson (2012) and Lei \& Church (2010) calculate the minimum travel time within a time window. On the other hand, Anderson et al. (2012) and Owen \& Levinson (2015) generate a continuous accessibility measure, accessibility being calculated at every minute. Farber et al. (2014) adopt a similar approach, measuring accessibility by transit to supermarkets at every minute of the day. Minute-by-minute accessibility measurements provide a higher resolution than previous approaches based on hourly or single departure time, hence accounting for flexible departure times.

While variation in transit service is accounted for in these studies, it is assumed that the opportunities at destinations (jobs in most studies) are available throughout the day. It does not take into account starting and leaving time constraints that are imposed on workers. For example, nurses or construction workers are more likely to work during non-typical working hours. This is 
especially relevant when travelling by transit, since transit service is generally lower during nontypical working hours. Legrain et al. (2015) address this limitation by combining variation in both transit and jobs availability. They measure accessibility at five different time periods during the day, matching transit time and number of jobs starting within a given time period.

Given the recent rise in the development of time-sensitive accessibility measures, assessing the different approaches is essential to help engineers and planners choose the method that best suits their needs. The utility of a measure depends on multiple criteria that are often in conflict with each other. On the one hand, measures must be theoretically sound, sensitive to multiple accessibility components (Geurs \& van Wee, 2004; Handy \& Niemeier, 1997). On the other hand, measures should be easy to operationalize, and easily interpretable and communicable (Geurs \& van Wee, 2004; Handy \& Niemeier, 1997). The choice of measure also depends on the objectives pursued by the engineers and planners (Geurs \& van Wee, 2004; Handy \& Niemeier, 1997).

Despite the recent progress in addressing the temporal component of accessibility, to our knowledge no study has yet assessed time-sensitive measures utility on a comparative basis. This study thus questions whether using time-sensitive measures, accounting for fluctuations in jobs availability and/or transit service throughout the day, improves their utility relatively to traditional constant measures.

\section{STUDY CONTEXT}

The research setting of this study is the GTHA, an urban area including the City of Toronto, the City of Hamilton and the Halton, Peel, Yorkland and Durham regions. The population of the GTHA $(5,574,140$ in 2011$)$ is constantly growing, primarily in the outer suburbs. In 2007 , the region had 2,678,170 workers and 2,759,180 jobs (Shearmur, Coffey, Dube, \& Barbonne, 2007). The GTHA 
draws workers from beyond its boundaries since the number of workers in the region is less than the number of jobs. Suburbanization of employment is also observed in the region (Shearmur et al., 2007).

The GTHA transit network is composed of a commuter rail system (the GO Train), a centrally located subway system and streetcar network, and bus services that are provided by eight different transit agencies. As shown in Figure 1, accessibility to all jobs available during the day by public transport calculated using the 8 am travel time is not evenly distributed across the region. Accessibility is greatest in the center and along the subway and commuter rail networks.

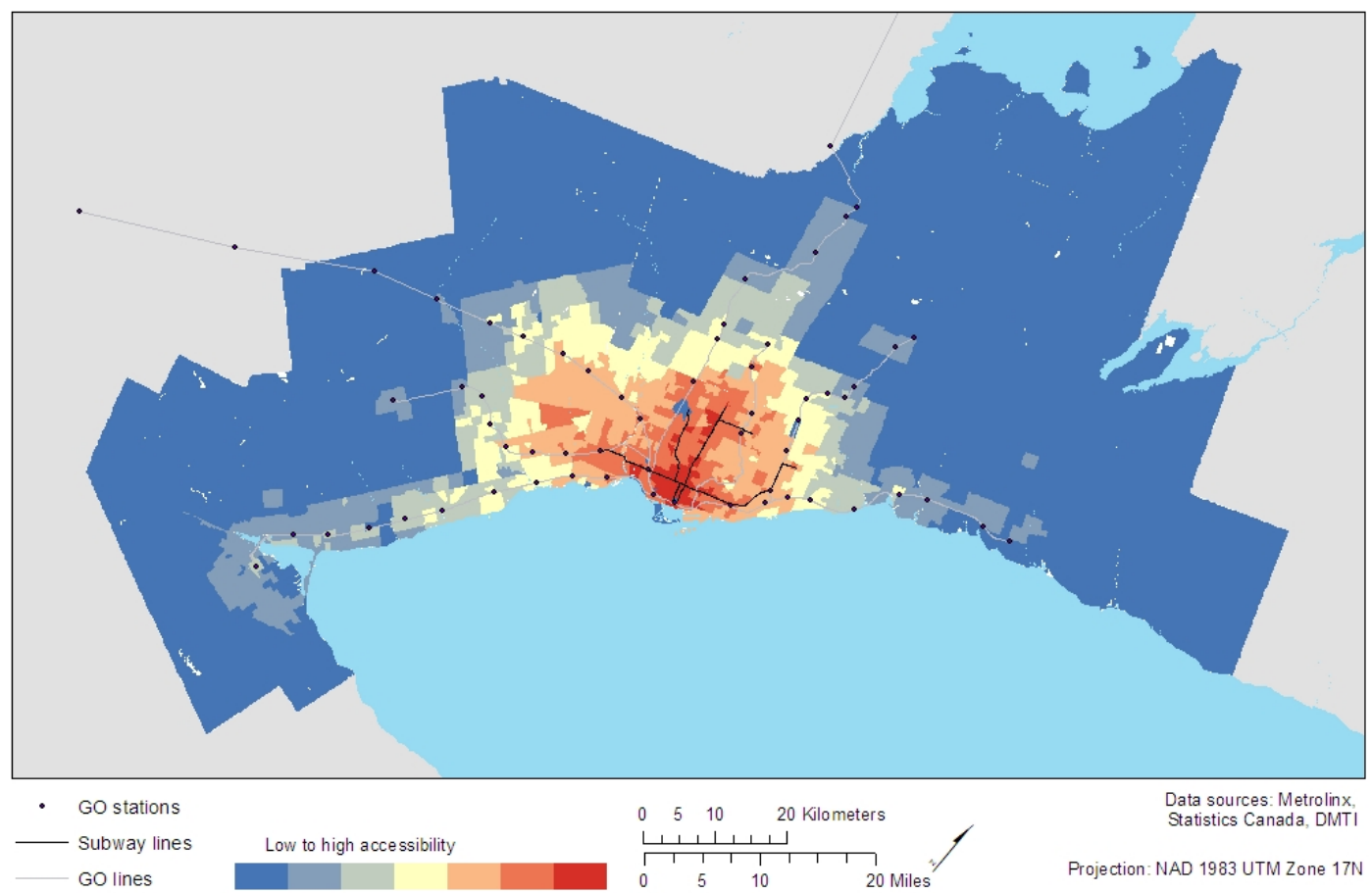

FIGURE 1 Accessibility at 8 am in the GTHA (number of jobs calculated with the gravitybased measure).

\section{DATA AND METHODOLOGY}

In order to compare the different methodological approaches of calculating accessibility, accessibility measures are generated based on different temporal measurements, using the same regional data. Three main data sources are used, all of which are at the census tract (CT) level. The 
first is the demographic census tract information from the Statistics Canada National Household Survey (NHS) collected in 2011 (Statistics Canada, 2011). This data includes household median income, unemployment rates, and percentage of immigrants and is used to determine social and economic deprivation.

The second dataset provides information regarding employed labour force commuting trips in the GTHA and is also obtained from the 2011 NHS (Statistics Canada, 2011). The number of trips from each $\mathrm{CT}$ to every other $\mathrm{CT}$ is provided for each travel mode. The data is organized in six time periods according to departure time ( 5 to 6 am, 6 to 7 am, 7 to 8 am, 9 am to noon, and noon to 5 am). Furthermore, the data is stratified by job category. Using this dataset, transit mode share and number of jobs are estimated at the census tract level for each time periods. The time periods used in this study are the ones provided by Statistics Canada. In order to avoid data suppression resulting from low amounts of data, data were aggregated from 9 am to noon, and from noon to 5 am by Statistics Canada. 341,875 workers departed to work between 9 am and noon, and 389,170, between noon and 5 am, comparatively to 747,765 departing between 7 and 8 am. The aggregation of data into extended time periods does not allow fully capturing the fluctuations throughout the day. Yet, to our knowledge, no data easily accessible to planners and researchers provides more detailed information on transit mode share and especially jobs availability, for the whole region in a 24 hour detail. Nevertheless, variations between peak and off-peak hours are captured in our study, as well as variations throughout the morning hours (between 6 am and $12 \mathrm{pm}$ ), when most people travel $(80 \%)$.

The final dataset is a transit travel time matrix based on May-June 2014 General Transit Feed Specification (GTFS) data for all eight transit agencies of the GTHA, calculated using the OpenTripPlanner Analyst provided by Conveyal (OpenTripPlanner, Accessed July 30, 2014). 


\section{Accessibility Measures}

Since the objective of this research is to compare measures of accessibility, the first step is to generate accessibility measures for all CTs in the study area. Based on previous research (ElGeneidy et al., 2016; Fan et al., 2012), three methods are chosen, which use different temporal fluctuations. Table 1 summarizes the three types of measure.

The constant measure reproduces the most common measure used in the literature (ElGeneidy \& Levinson, 2006; Geurs \& van Wee, 2004). It uses constant travel time and number of jobs across the day. The travel time is calculated based on an 8 am departure time, while the number of jobs corresponds to the total number of jobs available throughout the day. The static measure also uses a constant (total) number of jobs, but takes into account transit service fluctuation across the day, as in most studies accounting for temporal variations. Accessibility is measured for each time period, using travel time for each time period. Finally, the dynamic measure accounts for transit service fluctuation across the day and, additionally, the fluctuation in jobs availability throughout the day. Only jobs with a starting time associated with each time period are counted.

\section{TABLE 1 Overview of the Accessibility Measures}

\begin{tabular}{|l|l|l|}
\hline Type of measure & Transit service & Jobs availability \\
\hline Constant & Constant (8 am travel time) & Constant (jobs available all day) \\
\hline Static & Variable & Constant (jobs available all day) \\
\hline Dynamic & Variable & Variable \\
\hline
\end{tabular}

\section{Travel Time, Number of Jobs and Accessibility}

Accessibility measures are all based on a travel time from each CT to every other CT and on the number of opportunities (jobs) available in each other CT. The transit travel time for each hour is measured for departures at the top of the hour. It calculates the shortest trip (if walking, then walking) from each CT to every other CT with the time departure being the beginning of the hour. 
For the 9 am to noon time period, the average travel time of the departure at 9 am, 10 am and 11 am is calculated. For the noon to 5 am time period, travel time at noon is used in order to represent off-peak travelling time. Calculating the travel time based on an hourly resolution (at the top of the hour in our case) is imposed given the need to match the data available for transit mode share and jobs availability.

The number of jobs available in one CT is calculated based on the number of workers arriving at the $\mathrm{CT}$ in question. The time period associated with the job is determined by the departure time of the worker, as provided in NHS commuting trips data (between 5 and 6 am, 6 and 7 am, 7 and 8 am, 9 am and noon, and noon and 5 am). Figure 2 shows the density of jobs in each CT across the day, which is generally higher between 7 to $8 \mathrm{am}$, and 8 to $9 \mathrm{am}$. 

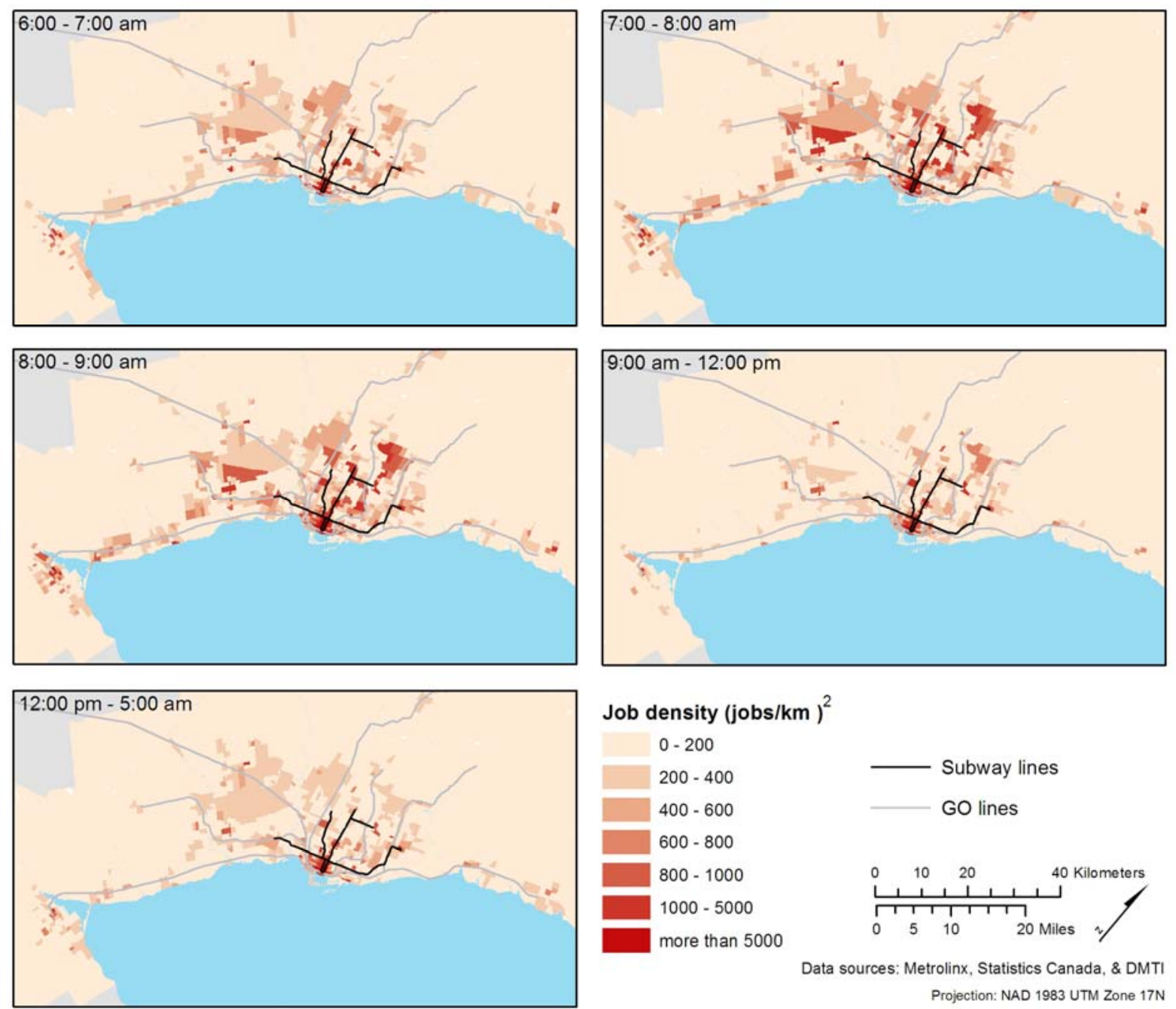

\section{FIGURE 2 Density of jobs throughout the day in the GTHA}

Both gravity-based and cumulative-opportunity measures were generated. However, since results were consistent and for simplicity reasons, this paper only presents the cumulative-opportunity approach. The cumulative-opportunity measure counts the number of jobs that are available from one CT within a certain travel time threshold, as indicated in equations 1 and 2.

$A_{i}=\sum_{j=1}^{n} O_{j} f\left(C_{i j}\right)$ 
$f\left(C_{i j}\right)=\left\{\begin{array}{l}1 \text { if } C_{i j} \leq t \\ 0 \text { if } C_{i j}>t\end{array}\right.$

Where $A_{i}$ is the accessibility at point $\mathrm{i}$ to all jobs at zone $\mathrm{j}, O_{j}$ the number of jobs in zone $\mathrm{j}$ and

$f\left(C_{i j}\right)$ the weighting function with $C_{i j}$ being the time cost of travel from $\mathrm{i}$ to $\mathrm{j}$ and $\mathrm{t}$, the travel time threshold. The weighting function used for cumulative-opportunity measure is a binary one, based on a travel time threshold. A 45-minute threshold is used in this study, as it showed a high correlation with the gravity-based measures. The estimation of the time cost of travel (travel times), $C_{i j}$, and the number of opportunities, $O_{j}$, depend on the method chosen (constant, static, dynamic) as indicated in Table 1.

Based on the cumulative opportunities, the relative accessibility is then calculated, since it allows for comparison and is easy to translate for policy-makers (Handy \& Niemeier, 1997). Relative accessibility is used to compare accessibility across the region, and is defined as the level of accessibility of a CT compared to the level of accessibility of all other CTs. As done in previous research (Foth, Manaugh, \& El-Geneidy, 2013; Manaugh \& El-Geneidy, 2012; Widener et al., 2015), standardized scores (z-scores) are used to express the relative accessibility.

\section{Comparison of Accessibility Measures}

Regression models predicting transit mode share based on accessibility by transit are developed in order to assess the accuracy of the three measures, as done in previous research (Owen \& Levinson, 2015). Since there is a well-established positive correlation between accessibility to jobs by transit and transit mode share (Dill et al., 2013; Legrain et al., 2015), the working assumption is that more accurate accessibility measures should result in better model fit to the data. Model fit is assessed based on adjusted $\mathrm{R}^{2}$ value, where a higher value can be interpreted as a reduction in error 
(Menard, 2000). Note that the Aikaike information criterion is not adequate to compare the models in this case, since we have the same amount of independent variables in all regression models.

\section{Description of the Regression Models}

Regression models are generated using the same dependent and independent variables, except for the accessibility parameters. The dependent variable, transit mode share for each time period, is calculated based on the NHS commuting trips data. Regarding the independent variables (other than accessibility), variables developed in previous studies (Foth et al., 2013; Legrain et al., 2015) are used. For example, we used a census demographic information variable, a composite indicator of social deprivation based on median income, unemployment rate, share of immigrant residents, and share of residents spending more than $30 \%$ of their income on housing was calculated for each CT. Then, CTs were placed into deciles from 1 to 10 (1 being the least socially deprived), and included in the models. Regarding the built environment and transit proximity, dummy variables are provided for location (urban core, inner suburbs, and outer suburbs), transit proximity (within $1 \mathrm{~km}$ of a subway and of a go station) and variables are calculated for the transit frequency (trips per hour) and the distance to highway on-ramp $(\mathrm{km})$. The mean distance $(\mathrm{km})$ travelled by people leaving the CT is used to control for travel habits in the CT. Finally, the population density (persons $/ \mathrm{km}^{2}$ ) is added as an independent variable, since it showed high significance in our models and increased the model fitting. This is consistent with previous research (Cervero, 2006; Pucher, 1988; Taylor, Miller, Iseki, \& Fink, 2009) suggesting that higher population density is related to higher transit quality (Taylor et al., 2009) and lower car ownership (Messenger \& Ewing, 1996) and thus results in higher transit share. It is important to note that all these variables included are used as controls.

Three transit share regression models are generated for each of the 5 time periods ( 6 am 
to $7 \mathrm{am}, 7$ am to $8 \mathrm{am}, 8$ am to 9 am, 9 am to noon, noon to $5 \mathrm{am}$ ), each one using a different type of accessibility measure (constant, static, dynamic), but keeping the other independent variables the same. Note that the 5 am to 6 am period is excluded from the analysis, given the high level of data suppression in the 2011 NHS and the low $\mathrm{R}^{2}$ value of the regression models (lower than 0.3 ).

Since previous research showed different findings when measuring accessibility to lowwage jobs and accessibility to all jobs (El-Geneidy et al., 2016), this study also assessed the three accessibility measures (constant, static and dynamic) for accessibility to low-wage jobs, using the methodology described previoulsy. Since the results between accessibility to all jobs and accessibility to low-wage jobs were consistent, only findings for accessibility to all jobs are presented in this paper.

\section{RESULTS: COMPARISON OF THE REGRESSION MODELS}

Generally speaking, the model outputs are consistent with previous literature (Dill et al., 2013; Legrain et al., 2015; Owen \& Levinson, 2015). Table 2 provides examples of regression models which are representative of the other models developed in this study. All variables are positively related to transit share, except for the distance to highway on-ramp, which is expected, and proximity to subway station for the $12 \mathrm{pm}$ to 5 am time period. In this case, the relationship is not significant and the confidence intervals range from negative to positive values. The location (in urban core or in inner suburbs), the social indicator decile and the accessibility to jobs are all highly significant explanatory variables, similar to previous studies (Dill et al., 2013; Legrain et al., 2015). Proximity to a GO station as well as distance to highway on-ramp have the same sign as in literature (Foth, Manaugh, \& El-Geneidy, 2014), but are not significant for all models (all time periods). Population density is significant for the 8 am to 9 am period, but not significant for the $12 \mathrm{pm}$ to 5 am time period. The model fit (adjusted $\mathrm{R}^{2}$ ) is lower for the $12 \mathrm{pm}$ to 5 am period, 
which is likely due to the lower amount of data. Within each time period, the confidence intervals of each coefficient overlap with each other, suggesting that the models reflect the same measures.

TABLE 2 Regression Result for Transit Share at 8 and noon to 5 am am Using Constant, Static, and Dynamic Accessibility Measures

\begin{tabular}{|l|l|l|l|l|l|}
\hline Measure & $\begin{array}{l}\text { Dynamic } \\
\mathbf{8 a m}\end{array}$ & $\begin{array}{l}\text { Static 8am } \\
\text { (constant) }\end{array}$ & $\begin{array}{l}\text { Dynamic } \\
\mathbf{1 2} \mathbf{p m ~ t o ~ 5} \\
\text { am }\end{array}$ & $\begin{array}{l}\text { Static 12 } \\
\text { pm to 5 am }\end{array}$ & $\begin{array}{l}\text { Constant } \\
\mathbf{1 2} \text { pm to 5 } \\
\text { am }\end{array}$ \\
\hline Transit frequency & 0.000096 & 0.0000832 & $0.00026^{*}$ & $0.00026^{*}$ & $0.00027^{*}$ \\
\hline In urban core & $0.16^{* * *}$ & $0.16^{* * *}$ & $0.18^{* * *}$ & $0.17^{* * *}$ & $0.17^{* * *}$ \\
\hline In inner suburbs & $0.16^{* * *}$ & $0.16^{* * *}$ & $0.19^{* * *}$ & $0.19^{* * *}$ & $0.19^{* * *}$ \\
\hline 1 km to subway station & $0.028^{*}$ & $0.028^{*}$ & -0.023 & -0.028 & -0.028 \\
\hline 1 km to GO station & 0.0058 & 0.0046 & 0.024 & 0.026 & 0.026 \\
\hline $\begin{array}{l}\text { Distance to highway on- } \\
\text { ramp }\end{array}$ & -0.00062 & -0.0006032 & -0.00025 & -0.00026 & -0.00016 \\
\hline Social indicator decile & $0.011^{* * *}$ & $0.011^{* * *}$ & $0.015^{* * *}$ & $0.015^{* * *}$ & $0.014^{* * *}$ \\
\hline Mean distance travelled & $0.0014^{*}$ & $0.0015^{*}$ & 0.00045 & 0.00036 & 0.00032 \\
\hline Population density & $0.0018^{* *}$ & $0.0019^{* *}$ & 0.00039 & 0.00021 & 0.00010 \\
\hline Accessibility to jobs & ${ }^{1} 0.060^{* * *}$ & ${ }^{2} 0.060^{* * *}$ & ${ }^{3} 0.041^{* * *}$ & ${ }^{2} 0.046^{* * *}$ & ${ }^{2} 0.048^{* * *}$ \\
\hline Constant & $0.030^{* *}$ & $0.031^{* *}$ & $0.061^{* * *}$ & $0.063^{* * *}$ & $0.066^{* * *}$ \\
\hline $\mathrm{R}^{2}$ (adjusted) & 0.7861 & 0.7854 & 0.6797 & 0.6821 & 0.6831 \\
\hline
\end{tabular}

${ }^{*} \mathrm{p}<0.05^{* *} \mathrm{p}<0.01 * * * \mathrm{p}<0.001$

${ }^{1}$ Available jobs at $8 \mathrm{am}$

${ }^{2}$ All jobs available during the day

${ }^{3}$ Available jobs between $12 \mathrm{pm}$ and 5 am

\section{Comparison of the Models}

Results of the regression models are presented in Table 3. First, all regression models that included an accessibility measure have more explanatory power (higher $\mathrm{R}^{2}$ ) than models without the accessibility parameter (defined as none category in Table 3). Accessibility variables prove to be highly significant in all cases. No matter which accessibility measure is chosen, its effect on transit share is observable.

Generally speaking, the sets of models using more detailed measures of accessibility (static and dynamic) do not provide better model fits than models using constant measures. Surprisingly, the values of the adjusted $\mathrm{R}^{2}$ are similar, and different models score higher and lower 
depending on the time period (Table 3). This is contrary to our expectations, which predicted consistently higher $\mathrm{R}^{2}$ for higher level of details in the measure. Different factors can explain these results. First, a smaller amount of data can lead to lower model fits. While the number of CTs is the same for all types of measures, the number of trips available for generating the measures is generally lower for the static measures, and even lower for the dynamic measures. The number of trips varies largely from one time period to another, with larger numbers found for the 7 to 8 am and 8 to 9 am periods. Regarding the dynamic measure, the number of jobs available is stratified by time periods, and thus necessarily lower than the number of jobs available throughout the day. This might explain the low fit of most of the dynamic measures.

TABLE 3 Performance of the Models $\left(\mathbf{R}^{2}\right.$-Adjusted Reported)

\begin{tabular}{|c|l|l|l|l|l|}
\hline $\begin{array}{c}\text { Accessibility } \\
\text { parameter }\end{array}$ & 6am & 7am & 8am & 9am to 12pm & 12pm to 5am \\
\hline None & 0.5042 & 0.6817 & 0.7625 & 0.6338 & 0.6707 \\
\hline Constant & $0.5259^{*}$ & $0.7070^{*}$ & $0.7854^{* *}$ & 0.6432 & $0.6831^{*}$ \\
\hline Static & 0.5258 & 0.7068 & $0.7854^{* *}$ & $0.6441^{*}$ & 0.6821 \\
\hline Dynamic & $0.5212^{* *}$ & $0.7052^{* *}$ & $0.7861^{*}$ & $0.6424^{* *}$ & $0.6797^{* *}$ \\
\hline
\end{tabular}

*Highest $\mathrm{R}^{2}$

**Lowest $\mathrm{R}^{2}$ (excluding the models with no accessibility parameter)

Correlation Between Accessibility Measures

Since no consistent difference is observed between the $\mathrm{R}^{2}$ values of different models, and the interpretation might be misleading due to different amounts of data, additional tests are needed. In order to compare the accessibility measures relatively to one another, the correlation between the measures is tested in the following section.

First, accessibility at $8 \mathrm{am}$, which reflects the constant measure, is compared to accessibility at other time periods for static and dynamic measures (Table 4). All measures are highly correlated, with the lowest coefficient being 0.95 . This shows that the relative accessibility of a CT at 8 am provides a valid approximation of its relative accessibility over the day both when using static and dynamic measures. 
TABLE 4 Correlation Coefficient between Accessibility Measured at Each Time Period and Accessibility at 8 am

\begin{tabular}{|c|c|c|}
\hline Time period & Static & Dynamic \\
\hline 6 am & 0.97 & 0.95 \\
\hline 7 am & 0.99 & 0.99 \\
\hline 8 am & 1 & 1 \\
\hline 9 am to $12 \mathrm{pm}$ & 0.98 & 0.98 \\
\hline 12 pm to $5 \mathrm{am}$ & 0.98 & 0.95 \\
\hline
\end{tabular}

$*$ Note that all correlations are statistically significant $(\mathrm{p}<0.05)$

A correlation matrix between all time periods was also generated and the coefficients are all higher than 0.95 . These findings show that the relative accessibility of a CT is more or less constant over the day. Put simply, CTs enjoying a relatively high level of accessibility at a given time period also enjoy a relatively high level of accessibility during other time periods. Figure 3 illustrates the relative accessibility of CTs in the GTHA at four different periods. The patterns of the relative accessibility are very similar from one period to another.
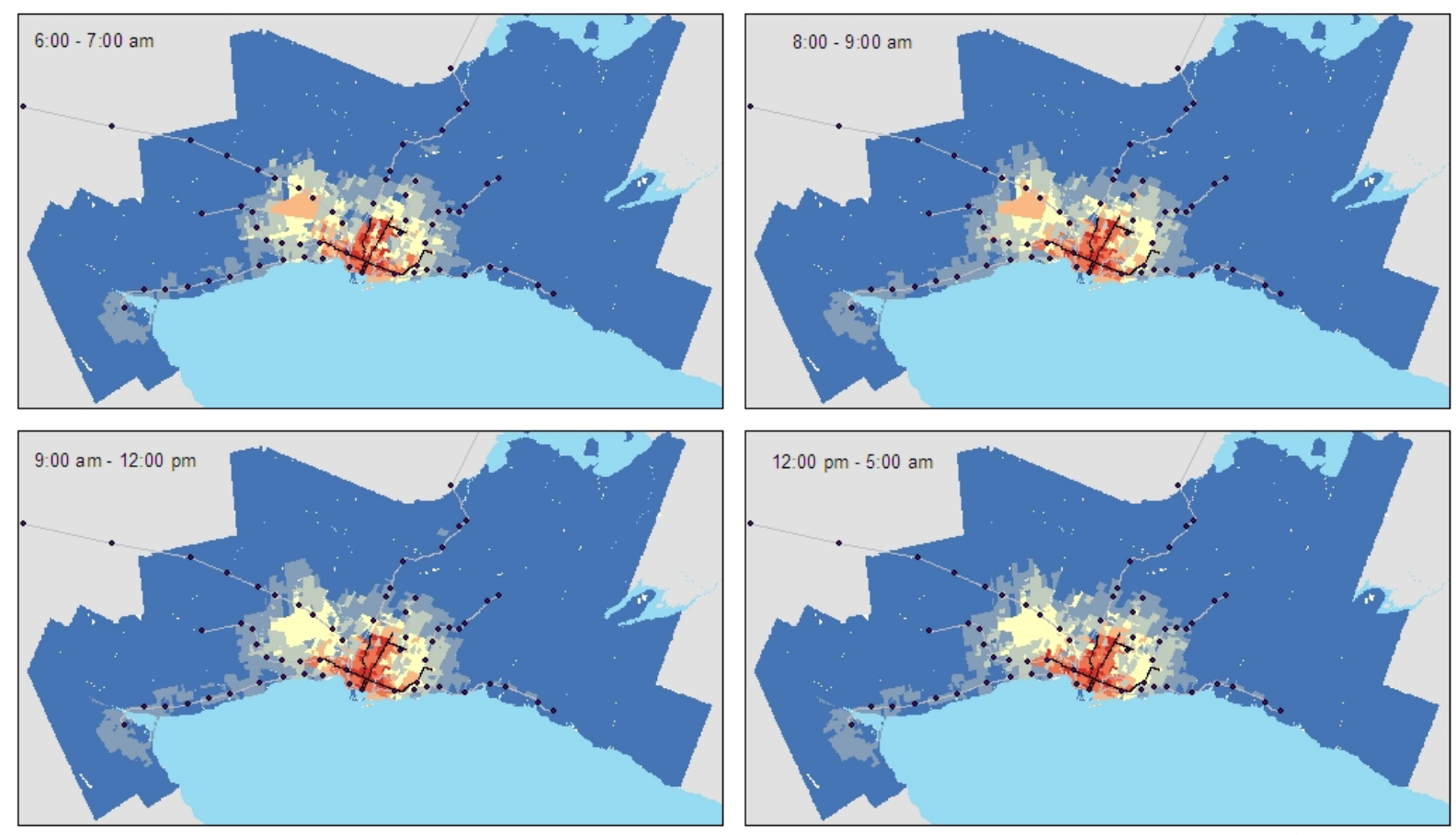

- GO stations

- Subway lines

Low to high relative accessibility

GO lines

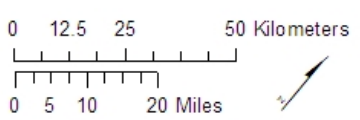

Data sources: Metrolinx Statistics Canada, DMT

FIGURE 3 Relative accessibility to available jobs in the GTHA. 
Second, the dynamic and static measures are compared by generating correlation matrices between these measures for all time periods. The two measures are highly correlated (all above 0.985) (Table 5). The results show that, generally speaking, CTs with lower accessibility to jobs available at a specific time period also have a lower accessibility to all jobs available throughout the day. As shown in FIGURE 4, the relative accessibility patterns using static or dynamic measures are very similar.

TABLE 5 Correlation Results between Static and Dynamic Measures for All Time Periods

\begin{tabular}{|l|l|}
\hline Time period & Coefficient \\
\hline $6 \mathrm{am}$ & 0.997 \\
\hline $7 \mathrm{am}$ & 0.999 \\
\hline $8 \mathrm{am}$ & 0.998 \\
\hline $9 \mathrm{am}$ to $12 \mathrm{pm}$ & 0.995 \\
\hline $12 \mathrm{pm}$ to $5 \mathrm{am}$ & 0.986 \\
\hline
\end{tabular}

$*$ Note that all correlations are statistically significant $(\mathrm{p}<0.05)$
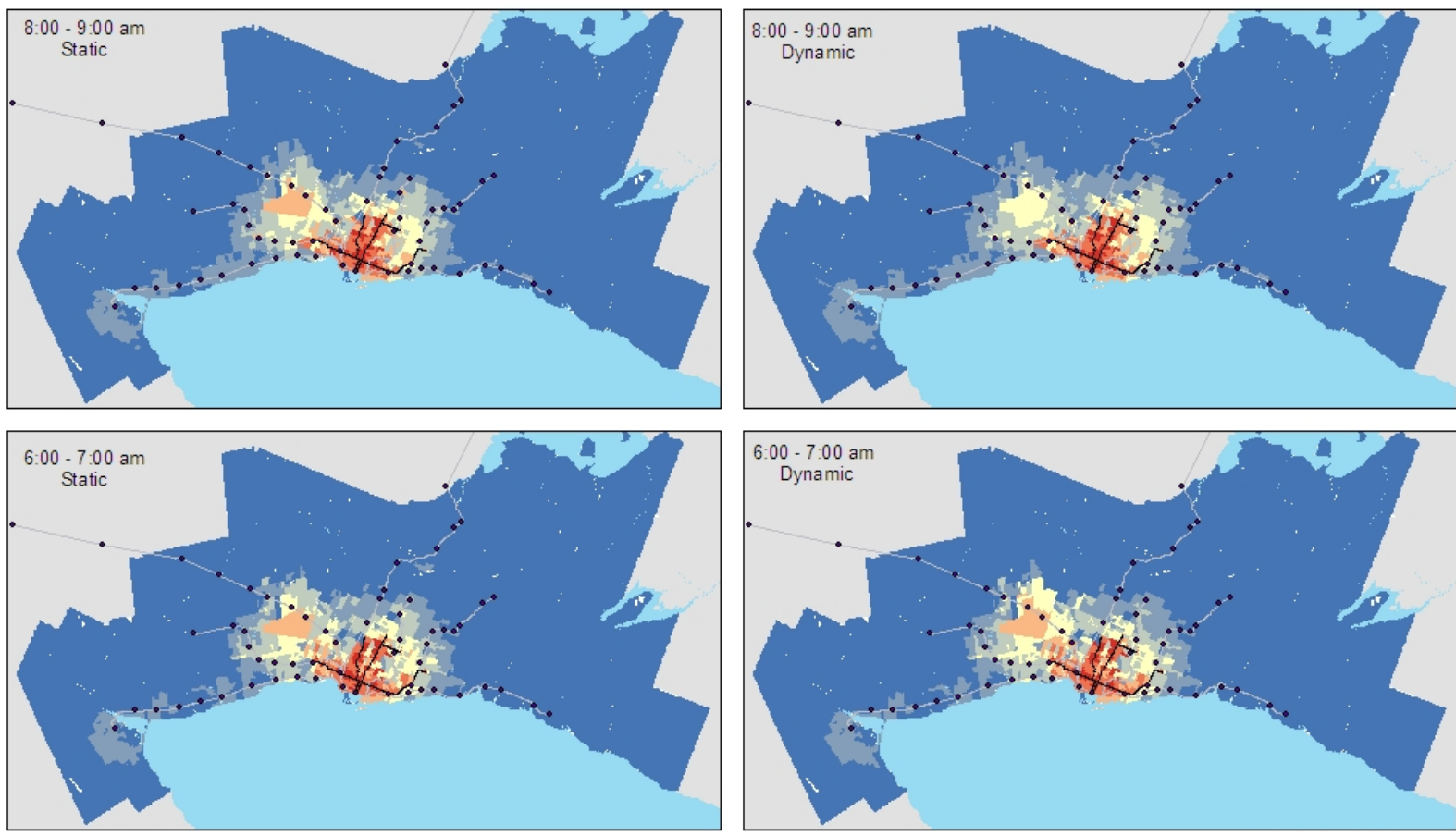

- GO stations

Subway lines

Low to high relative accessibility GO lines

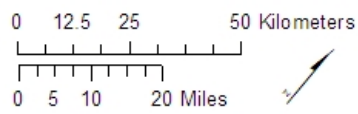

Data sources: Metrolinx Statistics Canada, DMT 
Based on the comparison between constant, static and dynamic measures, it is possible to conclude that the relative accessibility at 8 am to all jobs available is generally constant over the day. CTs enjoying a higher level of accessibility at 8 am to all jobs also enjoy higher levels of accessibility at other time periods to jobs available at that time period.

\section{DISCUSSION AND CONCLUSION}

From a general perspective, this research shows that the relative accessibility of a CT in the GTHA at 8 am to all jobs is representative of its relative accessibility throughout the day. No major or consistent differences are found in the quality of the regression models using constant, static or dynamic measures. Furthermore, constant, static and dynamic measures are highly correlated (above 0.95 in all cases). Relative accessibility is constant across time periods (using all-day jobs or only available jobs), showing that the CTs enjoying a higher level of transit service at a certain time period also enjoy a higher level of service at other time periods. In the same way, CTs with access to a larger amount of jobs, all jobs taken into account, also have access to a larger amount of jobs when only available jobs are accounted for. This is in line with El-Geneidy et al. (2016) and Legrain et al. (2015), who find consistent travel times and accessibility results across all time periods.

From a planning and engineering perspective, several factors have to be taken into account when choosing an appropriate and meaningful accessibility measure. From a theoretical perspective, it should address transport and land-use systems, temporal fluctuations as well as individual needs (Dodson et al., 2007; Geurs \& van Wee, 2004). All three methods address the transport and land-use components and can take into account individual needs by stratifying the data. The dynamic measure is the theoretically most sound, since it accounts for variations in transit service and in opportunities. A second factor to be addressed is the data requirements (Geurs 
\& van Wee, 2004; Handy \& Niemeier, 1997). In this regard, the constant measure generally uses data that is widely available in most regions. The constant measure is based on travel time calculated at $8 \mathrm{am}$, which is generally the time period with the largest number of trips. Additionally, it does not require a stratification of data by time period, which otherwise reduces the amount of data available for calculating accessibility. Furthermore, an appropriate measure is one that is intuitive and easily interpretable and communicable (Geurs \& van Wee, 2004; Páez et al., 2012). These criteria point towards simpler measures, which are easier to understand (Handy \& Niemeier, 1997). The constant measure, simply understood as the number of jobs reachable in a region using transit at $8 \mathrm{am}$, is the most easily communicable. In the same vein, the cumulative-opportunity measure directly represents the number of opportunities available within a certain travel time and might be more easily communicable. Also, the constant cumulative-opportunity measure is easier to generate and requires less time and data resources. Finally, measures have to be empirically sound to be meaningful to policy makers. As indicated in the results, all measures are highly correlated and thus provide a sound measure of the relative accessibility in the GTHA. Relative accessibility to all jobs at 8 am is representative of relative accessibility at other time periods. Although previous studies support time-sensitive accessibility metrics (El-Geneidy et al., 2016; Farber et al., 2014; Owen \& Levinson, 2015), the findings of this study suggest that a constant measure is appropriate for measuring the relative accessibility across CTs. In the same way, cumulative-opportunity accessibility, which is highly correlated to gravity-based accessibility, is representative of regional accessibility. This is in line with previous studies (El-Geneidy \& Levinson, 2006).

All factors considered, the results suggest that the constant measure based on cumulative opportunities, most often used by planners and engineers, is appropriate and meaningful to assess relative accessibility to jobs in the GTHA, at the regional scale. While theoretically less sound, the 
constant measure is simpler and easily communicable. Although more detailed approaches are expected to provide more accurate measures, their accuracy is compromised by the reduction of usable data. These findings also support the use of aggregated data in extended time periods. As the amount of employees departing to work between noon and 5 am is very low $(389,170$ comparatively to 747,765 between 7 and $8 \mathrm{am}$ ), it is expected that using smaller time periods would result in very low amount of data and hence compromise improvements in measure accuracy. Coming back to our general findings, while other North American cities with similar characteristics are expected to yield the same results, further research is needed to test these results in different contexts.

The conclusion of this research might appear contradictory to Owen \& Levinson's (2015) study, which shows that using time-averaged accessibility and variation over the day increases the quality of mode share regression models in the Twin Cities metropolitan area. However, taking into account that planners want to balance between the accuracy and the simplicity of a measure (Geurs \& van Wee, 2004), and given the very subtle increase in $\mathrm{R}^{2}$ and the complexity of the measure developed by Owen \& Levinson (2015), our conclusion still holds; since the relative accessibility of a CT is constant over the day, the constant measure is appropriate for engineers and planners investigating geographic disparities in regional accessibility to jobs. It is however important to note that our measures, based on a hourly resolution, do not fully account for transit frequency variations as they might be capturing repitious cycles based on hourly departures (for examples trains leaving at 7:05, 8:05, 8:35 and 9:05). Yet, as exemplified by Owen \& Levinson's continuous approach (2015), generating accessibility measures that fully account for transit frequency requires substantial additional data and operationalisation resources that might not be easily available to planners. To overcome this limitation, simple transit frequency indicators can be used together with accessibility measures, as done in previous research (Mavoa et al., 2012). 
To conclude, the constant approach provides an appropriate measure for policy-makers interested in relative accessibility, which can be used to better understand social equity or a transit share in a region. However, it is not excluded that different goals might require more detailed temporal measurements. For example, transit agencies specifically interested in transit service fluctuation or in absolute levels of accessibility throughout that day (for example, setting minimal threshold for different time periods) might be interested in static and dynamic accessibility measures. Additionally, accessibility to other types of opportunities, such as health care services, leisure areas and retail stores might be more sensitive to temporal fluctuations. Further investigations are thus suggested regarding the utility of static and dynamic measures for other transportation planning goals.

This work highlights the need to address the gap between accessibility research and its application in planning, by taking into account the usability of the measure. Theoretical developments of accessibility measures need to come with a reflection regarding their application in the field of planning.

\section{REFERENCES}

Anderson, P., Owen, A., \& Levinson, D. (2012). The time between: Continuously-defined accessibility functions for schedule-based transportation systems. Paper presented at the 92nd Annual Meeting of the Transportation Research Board.

Banister, D. (2008). The sustainable mobility paradigm. Transport Policy, 15(2), 73-80. doi:10.1016/j.tranpol.2007.10.005

Boschmann, E., \& Kwan, M. (2008). Towards socially sustainable urban transportation: Progress and potentials. International Journal of Sustainable Transportation, 2(3), 138-157.

Cervero, R. (2006). Alternative approaches to modeling the travel-demand impacts of smart growth. Journal of the American Planning Association, 72(3), 298.

Dill, J., Schlossberg, M., Ma, L., \& Meyer, C. (2013). Predicting transit ridership at the stop Level: The role of service and urban form. 92nd Annual Meeting of the Transportation Research Board.

Dodson, J., Gleeson, B., Evans, R., \& Sipe, N. (2007). Investigating the social dimensions of transport disadvantage II: From concepts to methods through an empirical case study. Urban Policy and Research, 25(1), 63-89. doi:10.1080/08111140701225511

El-Geneidy, A., Buliung, R., Diab, E., van Lierop, D., Langlois, M., \& Legrain, A. (2016). Non-stop equity: Assessing daily intersections between transit accessibility and social disparity across the Greater Toronto and Hamilton Area. Environment and Planning B: Planning and Design.

El-Geneidy, A., \& Levinson, D. (2006). Access to destinations: Development of accessibility measures. Retrieved from Minnesota: 
Fan, Y., Guthrie, A., \& Levinson, D. (2012). Impact of light rail implementation on labor market accessibility: A transportation equity perspective. Journal of Transport and Land Use, 5(3).

Farber, S., Morang, M., \& Widener, M. (2014). Temporal variability in transit-based accessibility to supermarkets. Applied Geography, 53, 149-159.

Foth, N., Manaugh, K., \& El-Geneidy, A. (2013). Towards equitable transit: Examining transit accessibility and social need in Toronto, Canada, 1996-2006. Journal of Transport Geography, 29, 1-10.

Foth, N., Manaugh, K., \& El-Geneidy, A. (2014). Determinants of mode share over time: How changing transport system affects transit use in Toronto, Ontario, Canada. Transportation Research Record(2417), 67-77. doi:10.3141/2417-08

Geurs, K., Krizek, K., \& Reggiani, A. (2012). Accessibility analysis and transport planning: an introduction. In K. Geurs, K. Krizek, \& A. Reggiani (Eds.), Accessibility Analysis and Transport Planning: Challenges for Europe and North America (pp. 1-12). Northampton: Edward Elgar Publishing Limited.

Geurs, K., \& van Wee, B. (2004). Accessibility evaluation of land-use and transport strategies: review and research directions. Journal of Transport Geography, 12, 127-140.

Hagerstrand, T. (1970). What about people in regional science? Papers of the Regional Science Association, 24, 7-21.

Handy, S. (2002). Accessibility- vs. mobility-enhancing strategies for addressing automobile dependence in the U.S. Retrieved from Davis:

Handy, S. (2008). Regional transportation planning in the US: An examination of changes in technical aspects of the planning process in response to changing goals. Transport Policy, 15(2), 113-126. doi:10.1016/j.tranpol.2007.10.006

Handy, S., \& Niemeier, D. (1997). Measuring accessibility: an exploration of issues and alternatives. Environment and Planning A, 29, 1175-1194.

Hansen, W. (1959). How accessibility shapes land use. Journal of the American Institute of Planners, 25(2), 73-76.

Legrain, A., Buliung, R., \& El-Geneidy, A. (2015). Who, what, when and where: Revisiting the influences of transit mode share. Transportation Research Record(2537), 42-51.

Lei, T., \& Church, R. (2010). Mapping transit-based access: Integrating GIS, routes and schedules. International Journal of Geographical Information Science, 24(2), 283-304.

Lucas, K. (2012). Transport and social exclusion: Where are we now? Transport Policy, 20, 105-113. doi:10.1016/j.tranpol.2012.01.013

Manaugh, K., Badami, M., \& El-Geneidy, A. (2015). Integrating social equity into urban transportation planning: A critical evaluation of equity objectives and measures in transportation plans in North America. Transport Policy(37), 167-176.

Manaugh, K., \& El-Geneidy, A. (2012). Who benefits from new transportation infrastructure? Using accessibility measures to evaluate social equity in transit provision. In K. Geurs, K. Krizek, \& A. Reggiani (Eds.), Accessibility and Transport Planning: Challenges for Europe and North America (pp. 211-227): Edward Elgar, London, UK.

Martens, K., Golub, A., \& Robinson, G. (2012). A justice-theoretic approach to the distribution of transportation benefits: Implications for transportation planning practice in the United States. Transportation Research Part A: Policy and Practice, 46(4), 684-695. doi:http://dx.doi.org/10.1016/j.tra.2012.01.004

Mavoa, S., Witten, K., McCreanor, T., \& O'Sullivan, D. (2012). GIS based destination accessibility via public transit and walking in Auckland, New Zealand. Journal of Transport Geography, 20, 15-22.

Menard, S. (2000). Coefficients of determination for multiple logistic regression analysis. The American Statistician, 54(1), 17-24.

Messenger, T., \& Ewing, R. (1996). Transit-oriented development in the sun belt. Transportation Research Record(1552), 145-153.

Miller, H. (2005). Place-based versus people-based accessibility. In D. Levinson \& K. Krizek (Eds.), Access to Destinations (pp. 63-89). Oxford University Press, UK: Elsevier. 
Moniruzzaman, M., \& Páez, A. (2012). Accessibility to transit, by transit, and mode share: application of a logistic model with spatial filters. Journal of Transport Geography, 24, 198-205.

Niedzielski, M., \& Boschmann, E. (2014). Travel time and distance as relative accessibility in the journey to work. Annals of the Association of American Geographers, 104(6), 1156-1182.

Olszewski, P., \& Wibowo, S. (2005). Using equivalent walking distance to assess pedestrian accessibility to transit stations in Singapore. Transportation Research Record(1927), 38-45.

OpenTripPlanner. (Accessed July 30, 2014). http://www.opentripplanner.org/.

Owen, A., \& Levinson, D. (2015). Modeling the commute mode share of transit using continuous accessibility to jobs. Transportation Research Part A: Policy and Practice, 74, 110-122. doi:10.1016/j.tra.2015.02.002

Páez, A., Mercado, R., Farber, S., Morency, C., \& Roorda, M. (2010). Accessibility to health care facilities in Montreal Island: An application of relative accessibility indicators from the perspective of senior and non-senior residents. International Journal of Health Geographics, 9(52), 1-15.

Páez, A., Scott, D., \& Morency, C. (2012). Measuring accessibility: Positive and normative implementations of various accessibility indicators. Journal of Transport Geography, 25, 141-153.

Polzin, S., Pendyala, R., \& Navari, S. (2002). Development of time-of-day-based transit accessibility analysis tool. Transportation Research Record(1799), 35-41.

Preston, J., \& Rajé, F. (2007). Accessibility, mobility and transport-related social exclusion. Journal of Transport Geography, 15, 151-160.

Pucher, J. (1988). Urban travel behavior as the outcome of public policy: the example of modal-split in Western Europe and North America. Journal of the American Planning Association, 54(4), 509520.

Shearmur, R., Coffey, W., Dube, C., \& Barbonne, R. (2007). Intrametropolitan employment structure: Polycentricity, scatteration, dispersal and chaos in Toronto, Montreal and Vancouver, 1996-2001. Urban Studies, 44(9), 1713-1738.

Statistics Canada. (2011). 2011 National Household Survey Retrieved from https://www12.statcan.gc.ca/nhs-enm/2011/dp-pd/dt-td/index-eng.cfm

Taylor, B., Miller, D., Iseki, H., \& Fink, C. (2009). Nature and/or nurture? Analyzing the determinants of transit ridership across US urbanized areas. Transportation Research Part A: Policy and Practice, 43(1), 60-77. Retrieved from http://ac.els-cdn.com/S0965856408001274/1-s2.0S0965856408001274-main.pdf? tid=8468d4c0-819c-11e5-9d55$\underline{00000 a a b 0 f 6 b \& a c d n a t=1446494674 \_ \text {aae } 7 \mathrm{fe} 108 \mathrm{~d} 55747 \mathrm{cbee} 9 \mathrm{e} 7 \mathrm{e} 01 \mathrm{~d} 2 \mathrm{bc} 960}$

http://ac.els-cdn.com/S0965856408001274/1-s2.0-S0965856408001274-main.pdf? tid=86c508d8-819c11e5-b236-00000aacb360\&acdnat $=1446494678$ dc6c66970a5d139b53d7bdac7b269ca0

Wangtu, X., Ding, Y., Zhou, J., \& Li, Y. (2015). Transit accessibility measures incorporating the temporal dimension. Cities, 46, 55-56.

Widener, M., Farber, S., Neutens, T., \& Horner, M. (2015). Spatiotemporal accessibility to supermarkets using public transit: An interaction potential approach in Cincinnati, Ohio. Journal of Transport Geography, 42, 72-83.

Zielstra, D., \& Hochmair, H. (2011). Comparative study of pedestrian accessibility to transit stations using free and proprietary network data. Transportation Research Record(2217), 145-152. 